\title{
O PROCESSO DE INCLUSÃO/EXCLUSÃO DAS PESSOAS COM DEFICIÊNCIA NO CONTEXTO DA REESTRUTURAÇÃO PRODUTIVA DO CAPITAL
}

\author{
Gedeli Ferrazzo ${ }^{1}$ \\ Claudinei Frutuoso ${ }^{2}$ \\ Márcia Ângela Patrícia ${ }^{3}$ \\ Marco Antônio de Oliveira Gomes ${ }^{4}$
}

\section{RESUMO}

Este artigo discute o processo de inclusão/exclusão das pessoas com deficiência no contexto da reestruturação produtiva do capital. Debate imprescindível perante o cenário de significativas mudanças que vêm ocorrendo ao longo das últimas décadas, nas relações entre capital e trabalho, particularmente pela crise estrutural do capitalismo que reflete nas relações estabelecidas entre capital e trabalho. Para tanto, o presente artigo tem como objetivo apresentar elementos que contribuem para o debate sobre a inclusão das pessoas com deficiências, no mercado de trabalho do Estado de Rondônia. A fim de alcançarmos o objetivo acima elencado, utilizamos, como referencial teórico, as principais contribuições Marx (1998, 1985, 1978), além de autores identificados com as proposições marxianas, tais como Saviani (2008, 2007, 2005), Kuenzer (2001, 2006), Mészáros (2004), entre outros. Com base no levantamento de dados da pesquisa, concluímos que o discurso hegemônico proclamado pelo capital responsabiliza os trabalhadores por não estarem qualificados para fazer frente às exigências do mercado de trabalho, o que exime grande parcela das empresas do não cumprimento da Lei $\mathrm{n}^{\circ}$ 8.213/91. Assim, a inclusão das pessoas com deficiências no mercado de trabalho se constitui apenas na defesa do princípio, não sendo acompanhada por uma política que de fato garanta o cumprimento da lei.

Palavras-chave: Processo de inclusão/exclusão. Pessoas com deficiência. Rondônia.

\section{THE PROCESS OF INCLUSION/EXCLUSION OF PEOPLE WITH DISABILITIES IN THE CONTEXT OF PRODUCTIVE RESTRUCTURING OF CAPITAL}

\begin{abstract}
This article discusses the process of inclusion/exclusion of people with disabilities in the context of the productive restructuring of capital. This debate is crucial upon a scenario with significant changes that have been occurring over the past few decades in the relationship between capital and labor, particularly caused by the structural crisis of capitalism which is reflected on the established relations between work and capital. Therefore, this article aims to introduce elements that contribute to the debate about the inclusion of people with disabilities in the labor market of the state of Rondônia. To achieve the objective part listed above, it is used, as methodological framework and main contributions, Marx $(1998,1985,1978)$, as well as authors identified with the Marxian propositions, such as Saviani (2008, 2007, 2005), Kuenzer (2001, 2006), Mészáros (2004), among others. Based on the data of this research, we conclude that the hegemonic discourse proclaimed by the capital charges the workers for not having the qualifications to face the labor market requirements, withdrawing a large part of the business to the responsibility to fulfill the Law n. 8.213/91. Thus, the inclusion of people with disabilities in the labor market remains on shallow initial defense, not being followed by a policy that grants the fulfillment of the law.
\end{abstract}

Keywords: Process of inclusion/exclusion. Disabled person. Rondônia. 


\section{INTRODUÇÃO}

Neste início do século XXI, tem se intensificado o discurso em prol da inclusão social, em específico de pessoas com deficiência, fomentando o debate tanto no campo educacional como no discurso "novidadeiro" pós-moderno. Tal apropriação elaborada no âmbito das necessidades do capital, em construir um Estado de ideologia única, tem levando muitos a acreditar que os ideais de igualdade e liberdade estão sendo concretizados, nesse modelo societário.

É preciso esclarecer que o capital, devido às rápidas e profundas transformações impostas pela reorganização do Estado Burguês, caracterizadas pelas reformas neoliberais e fortalecidas pela reestruturação produtiva, inaugurou mudanças definitivas nas condições de trabalho, o que correspondeu ao crescimento das taxas de desemprego, na desarticulação do movimento sindical, culminando no aprofundamento da desigualdade substantiva daqueles que vivem do trabalho.

Neste sentido, o presente estudo visa apreender os determinantes que engendram o processo de inclusão das pessoas com deficiência, no mercado de trabalho, por compreender que o trabalho se constitui como elemento primordial no processo de inclusão, na medida em que as condições materiais determinadas pelo antagonismo das classes sociais, em última instância, fundamentam as condições sociais. Dessa forma, este artigo se norteou pela questão a ser investigada: qual é a efetividade da Lei $\mathrm{n}^{\circ}$ 8.213/91 no Estado de Rondônia?

Para responder a tal questionamento, realizamos a pesquisa em três etapas: a primeira etapa versou no levantamento documental e bibliográfico, na contextualização da produção acumulada na área, a fim de oferecer uma visão teórica na orientação da análise dos dados. A segunda etapa foi conduzida por meio de questionários direcionados ao Ministério do Trabalho e do Emprego do Estado de Rondônia (MTE) e a agência estadual do Sistema Nacional de Emprego (SINE). A última etapa teve por objetivo a análise dos dados coletados e a compatibilidade das políticas inclusivas. É evidente, na análise da pesquisa, que o discurso hegemônico burguês, da inclusão, como medida para a manutenção das desigualdades sociais, ancorado no ideário de igualdade de oportunidades, do respeito à diversidade, da valorização das diferenças, produz a consciência social e coletiva em conformidade as necessidades do capital. Os velhos problemas sociais são reduzidos a ações particularizadas, minimizadas pela lógica do individualismo.

\section{O TRABALHO COMO ATIVIDADE VITAL, MEIO PELO QUAL O HOMEM GARANTE A SOBREVIVÊNCIA E SE TORNA HUMANIZADO}

O contexto do mundo do trabalho se caracteriza por mudanças ocorridas durante os séculos para satisfazer as necessidades do homem, sendo que o conceito, a classificação e o valor atribuído ao trabalho variam conforme cada sociedade. Ao longo da história, caracterizaram-se diferentes modos de produção no seio da sociedade: primitivo, asiático, escravista, feudal e capitalista. Esse último, no caso, surgiu do esgotamento do modo de produção feudal, passando por diferentes fases de organização, do regime manufatureiro, caracterizado como processo primitivo de acumulação de capital ao advento da microeletrônica. Uma vez consolidada as relações capitalistas, o regime industrial foi o responsável pelo surgimento de um trabalhador fragmentado, que já não controla e não se reconhece na produção. Marx já postulava a crítica a tal evolução que, segundo ele, fragmentava o ato do trabalho em si. 
Pela introdução das máquinas desenvolveu-se a divisão do trabalho no interior da sociedade, simplificou-se a tarefa do operário no interior da oficina, foi reunido o capital, o homem foi ainda mais despedaçado (MARX, 1978, p. 155).

Para a compreensão de tal desfacelamento da atividade humana conhecida como trabalho, Saviani (2007, p. 154) caracteriza o trabalho como ato de agir sobre a natureza, transformando-a em função das necessidades humanas. De acordo com o autor, a essência humana não é dada ao homem; não é uma dádiva divina ou natural; não é algo que precede à existência do homem, mas, ao contrário, a essência humana é produzida pelos próprios homens, por meio do trabalho. Pois, para o homem garantir sua existência, não são suficientes suas bases biológicas, mas ele necessita apropriar-se da cultura existente, transformando a natureza, por meio do trabalho e produzindo novos instrumentos culturais e sociais. Assim, o homem produz sua condição humana pelo trabalho.

Contraditoriamente, o advento da indústria moderna conduziu a uma crescente simplificação do trabalho, reduzindo a necessidade de qualificação específica, viabilizada pela introdução da maquinaria, que passou a executar a maior parte das funções manuais. Pela maquinaria, que não é outra coisa senão trabalho intelectual materializado, deu-se visibilidade ao processo de conversão da ciência, potência espiritual, em potência material (SAVIANI, 2007, p. 154). Dessa forma, configurou-se a desumanização do homem em caráter de exploração na produção do seu próprio sustento.

O homem se humaniza (ou se desumaniza) pelo trabalho na medida em que é por esta prática que ele transforma a realidade (natureza) adaptando-a as suas necessidades. Ao transformá-la, ele mesmo se transforma mediado pelas relações que estabelece no processo de produção (BACZINSKI; PITON; TURMENA, 2008, p. 1-3).

Tal processo se estabelece no final do século XIX, com a introdução do modo de produção taylorista/fordista, no qual se operou a transferência das funções manuais para as máquinas, contudo cabe ressaltar que a invenção da maquinaria moderna é uma produção humana, dirigida para resolução de um determinado problema e apropriada pelo capital na exploração e intensificação da força de trabalho disciplinada. Contudo a intensificação do trabalho no final do século XX pelo modo de produção toyotista, transferio para as máquinas as operações intelectuais. Se a base eletromecânica demandava uma força de trabalho mediada por habilidades físicas específicas, a mudança para a base microeletrônica passa a ser mediada por um domínio de habilidades e conteúdos cognitivos superiores, sem que isso signifique o domínio da produção pelo trabalhador.

Nesse contexto, nas novas formas de produção material, o trabalhador não precisa, necessariamente, saber o que está produzindo, apenas precisa saber desempenhar sua função, ou seja, ele não sabe o que produz e nem para quem está produzindo. Ele perde a noção do valor da sua força de trabalho, sendo que, para ele, é mais simples vendê-la e deixar tudo nas mãos de quem a comprou. Para uma sociedade capitalista, produção tem como sinônimo lucro, ou seja, quanto mais se produz, mais capital é gerado para a empresa (ALBORNOZ, 2008, p. 171).

Ao evidenciar a inovação técnica e a organização da produção e do processo de trabalho, "adestrando" o trabalhador ao sistema da produção em massa de mercadoria, constatam-se materializações históricas desta contradição, ou seja, o avanço tecnológico converte-se, sob as relações sociais de produção capitalista, em instrumento de maximização da 
exploração da força de trabalho, ampliando a marginalização social através do crescente desemprego mantido sob controle (SAVIANI, 2005, p. 21).

Com efeito, o modo de produção de bens e serviços sofreu profundas alterações nas últimas três décadas. A empresa institucional do passado dá lugar à empresa "enxuta", competitiva, transnacional, com "reengenharias" de toda ordem e reorganizada em padrões toyotistas. De modo que os princípios do toyotismo estabelecem novas formas de organização do processo de produção, engendrados pela lógica do Just in Time, de produzir somente o necessário, no momento necessário e na quantidade necessária, com um estoque mínimo de matéria-prima e produtos. Quanto à força de trabalho, intensifica-se a flexibilização das relações de trabalho (terceirização, subcontratações etc.), bem como se modela um novo tipo de trabalhador que não basta ser disciplinado, mas esse deve estar habilitado para muitas funções (multifuncionalismo). Para Belluzzo:
A argumentação liberal-conservadora sustenta que o aparecimento e o crescimento dessas formas espúrias de ocupação da força de trabalho, bem como a queda no valor real das remunerações, devem ser creditados ao egoísmo e ao "corporativismo" dos que ainda se apegam à segurança e à garantia dos "velhos empregos". Essa resistência às "inevitáveis" transformações tecnológicas e organizacionais acaba prejudicando a oferta de empregos, porque as empresas, diante da concorrência exacerbada, só podem responder ao desafio com o avanço da "flexibilização", contornado a legislação que pretende regulamentar as relações trabalhistas $(2012$, p. 17).

Consequentemente, desse novo modelo de produção, surge a necessidade de reconfiguração do modelo educacional, pois, mudando as bases materiais de produção, é preciso modelar o novo trabalhador para que atenda às demandas de um processo produtivo cada vez mais esvaziado. Assim, a escola, por sua vez, constitui-se fórum privilegiado como uma das formas de materialização do processo de produção engendrado. Dessa forma, a finalidade do trabalho pedagógico articula-se ao projeto capitalista, disciplinando para a vida social e produtiva, em conformidade com as especificidades que os processos de produção, em decorrência do desenvolvimento das forças produtivas, vão assumindo. Exige-se do trabalhador capacidades cognitivas e comportamentais flexíveis de modo que se adaptem, com rapidez e eficiência, a situações novas, bem como criem respostas para situações imprevistas, denominadas de polivalência. Por polivalência, entende-se a ampliação da capacidade do trabalhador para aplicar novas tecnologias, sem que haja mudança qualitativa dessa capacidade. Portanto, nada mais é que a inter-relação entre conteúdos fragmentados, sem superar os limites da divisão e da organização segundo os princípios da lógica formal, ou seja, uma junção de partes sem que signifique uma nova totalidade. A escola reproduz esta fragmentação, através de seus conteúdos, métodos e formas de organização e gestão (KUENZER, 2006).

Contudo, a relação dialética entre o mundo do trabalho e a educação, aos moldes toyotista, equivalem à lógica da inclusão excludente, de modo que a professada universalização educacional aumenta seus índices de inclusão, em termos quantitativos, mas esvazia os processos educativos, em que as estratégias inclusivas têm por finalidade ampliar o número de matriculados, articulando a falsa ideologia neoliberal, através da qual, ao se disponibilizar educação, promove-se a equiparação de oportunidades, independente das condições materiais de existência. 
Compreende-se que o processo educativo não tem o poder de mudar a lógica destrutiva do capital, no entanto ele é um instrumento de luta para a classe trabalhadora a partir do momento que se apropria do conhecimento historicamente acumulado pela humanidade, possibilitando, assim, instrumentalizar-se com conhecimentos pertencentes ao mundo da cultura, criando-os e reelaborando-os. A classe trabalhadora (incluímos aqui os excluídos de forma geral) necessitam dominar aquilo que os dominantes dominam, qual seja o conhecimento científico, para lutar com ferramentas iguais com a classe opressora. Dessa forma, a educação como processo não material se torna parte do trabalho material (SAVIANI, 2008).

\section{AS REFORMAS IMPOSTAS PELA REESTRUTURAÇÃO PRODUTIVA DO CAPITAL E AS PESSOAS COM DEFICIÊNCIAS}

Ao analisarmos as condições de existência das pessoas com deficiência ao longo da história, nota-se que as práticas e concepções refletiram o extermínio, o abandono e a institucionalização delas em distintas sociedades.

Nas sociedades primitivas, organizadas pelo modo de produção comunal, em que o nível de desenvolvimento das forças produtivas era baixíssimo, obrigando os homens a se deslocarem constantemente, na dependência do que a natureza lhes proporcionava, as pessoas com deficiências, que apresentavam alguma dificuldade ao grupo, atrapalhando o deslocamento, eram abandonadas ou exterminadas. De acordo com Silva:

[...] a não sobrevivência ocorria mais devido à pressão causada pelas dificuldades na obtenção de alimentos ou mesmo de autossuficiência e agilidade para cuidar de si mesmo em hora de perigo, quando não devido a questões de utilidade do componente do grupo (1986, p. 48).

Nesse sentido, pode-se aferir que procedimentos como o extermínio, a eliminação e o abandono das pessoas com deficiência, nesse período, justificavam-se devido ao baixo desenvolvimento das relações sociais de produção, pois tais pessoas atrapalhavam o deslocamento ágil do grupo, na busca de alimentos e nos afazeres.

Contudo, o desenvolvimento das relações de produção, por meio do aperfeiçoamento dos instrumentos existentes, bem como o aparecimento do pastoreio, da agricultura e a utilização de metais, possibilitaram que a força do trabalho humano criase mais produtos do que os necessários ao sustento de cada produtor (ENGELS, 1984, p. 181). Tais acontecimentos, atrelados ao advento da propriedade privada, determinaram na desagregação do comunismo primitivo e a consolidação do modo de produção escravista grega e romana, a qual tornou possível à classe dos proprietários viver sem trabalhar, dedicando-se ao "ócio digno".

Uma das práticas que se destacam ao modo de produção escravista junto às pessoas com deficiência é a eliminação do meio social dessas, devido à supervalorização da beleza, da força física e intelectual. Como se pode destacar na afirmação de Platão (apud SILVA, 1986, p. 124): "no que concerne aos que receberam corpo mal organizado, deixa-os morrer".

$\mathrm{Na}$ Antiguidade, tanto grega como romana, uma criança que nascia com alguma deficiência era submetida a uma análise para qualificar sua "monstrualidade", e, assim, decidia-se que atitude mais cabível seria tomada. Isso referente às crianças que nasciam no meio aristocrático ou filhos de trabalhadores, como os artesões. No caso dos escravos, possuindo alguma deficiência que os impedisse de trabalhar e de produzir seu próprio meio 
de sobrevivência, eram eliminados, e aqueles poucos que sobreviviam e não tinham como se sustentar acabavam esmolando ou, muitas vezes, eram usados nos espetáculos circenses, como figuras bizarras, passando, assim, a ter algum valor mercantil. Segundo Silva:

Cegos, surdos, deficientes mentais, deficientes físicos e outros tipos de pessoas nascidas com malformações eram também de quando em quando ligados a casas comerciais, a tavernas, a bordéis, bem como a atividades dos circos romanos, para serviços simples e às vezes humilhantes, costume esse que foi adotado por muitos séculos na História da Humanidade (1986, p. 130).

Com a ruptura do modo de produção escravista e a ascensão da nova ordem de produção feudal, são estabelecidas novas formas de relações sociais de produção, possibilitando às pessoas com deficiência desenvolverem alguma atividade dentro da organização produtiva familiar. Já aquelas que apresentavam uma deficiência acentuada eram segregadas do convívio social. Essa prática, conhecida como institucionalização, foi fortemente impulsionada pelo cristianismo, que já havia se tornado a religião oficial do Império Romano nos últimos séculos de existência do modo de produção escravista. $\mathrm{O}$ cristianismo condenava a eliminação das pessoas com deficiência, pois suas almas perteciam a Deus, mas o tratamento dispensado a elas era de sujeitos derivados do pecado ou até mesmo de forças demoníacas.

Dessa forma, a Igreja Católica começou a estimular a organização de hospitais, asilos e hospícios para recolher aqueles que não se integravam ao modo de produção feudal, com o objetivo de assisti-los e, ao mesmo tempo, restringir seus movimentos a um determinado território. Aqueles que não se encaixavam nas instituições e tampouco ao modo de produção feudal sobreviviam esmolando pelas cidades.

Com a expansão comercial e marítima do século XVI, fruto do avanço das forças produtivas, verifica-se o incremento das manufaturas e o avanço das ciências físicas e naturais, possibilitando o maior domínio da natureza e as bases para o processo de acumulação primitiva do capital.

Tal contexto favoreceu a consolidação do modo de produção capitalista, de modo que as formas de organização produtivas típicas da Idade Média, como as corporações de ofício, são superadas pelas manufaturas, os escravos/servos se convertem em trabalhadores assalariados em corpo disciplinado, afim de aumentarem a produção para atender à demanda da nova classe exploradora, a burguesia. Para Marx (1998, p. 30): “A moderna sociedade burguesa, saída do declínio da sociedade feudal, não aboliu as oposições de classes. Apenas pôs novas classes, novas condições de opressão, novas configurações de luta, no lugar das antigas".

O modo de produção capitalista, impulsionado pelo crescimento acelerado do comércio de mercadorias, estabeleceu uma nova forma de organização social, na qual as relações humanas passaram a ser estabelecidas em função do processo produtivo voltado para a acumulação de lucro e expropriação do trabalhador.

[...] de um lado proprietários de dinheiro, de meios de produção e de vida, aos quais o que interessa é valorizar a soma de valor por eles possuída por meio da compra de força de trabalho alheia; do outro lado trabalhadores livres, vendedores da força de trabalho própria e por isso vendedores de trabalho (MARX, 1985, p. 673).

A ascensão da nova ordem social e econômica capitalista exigia um novo tipo de trabalhador. Já não bastaria que fosse piedoso e resignado; agora devia aceitar trabalhar 
para outro e fazê-lo nas condições que esse outro lhe impusesse. Nesse modelo, os princípios do mercado se tornam referencial obrigatório para todas as dimensões da vida social, e aqueles que não se ajustam à lógica do processo produtivo passam a ser considerados como perturbadores da ordem social vigente. Segundo Marx:

A legislação os tratava como criminosos "voluntários" e supunha que dependia de sua boa vontade seguir trabalhando nas antigas condições, que já não existiam. [...] Na Inglaterra, essa legislação começou sob Henrique VII. Henrique VIII, 1530: Esmoleiros velhos e incapacitados para o trabalho recebem uma licença para mendigar. Em contraposição, açoitamento e encarceramento para vagabundos válidos. Eles devem ser amarrados atrás de um carro e açoitados até que o sangue corra de seu corpo, em seguida devem prestar juramento de retornarem a sua terra natal ou ao lugar onde moraram nos últimos 3 anos e "se porem ao trabalho" (1985, p. 356).

Dentre esses, encontravam-se as pessoas com deficiência que, juntamente com outros "desajustados", eram internadas em asilos, hospícios, manicômios etc., prática denominada como institucionalização. Para Bueno (1993, p. 63), "o que ocorreu, na verdade, foi o isolamento daqueles que interferiam e atrapalhavam o desenvolvimento da nova forma de organização social, baseada na homogeneização e na racionalização". Se no modo de produção feudal a religião era suficiente para obter a submissão passiva do camponês, a ascensão da burguesia liberal moderna necessitou recorrer à escola, enquanto sistema formal de educação, para garantir a submissão ativa que o trabalho industrial exigia do operário assalariado.

Na segunda metade do século XVIII, surgem na Europa as primeiras instituições educacionais destinadas às pessoas com deficiência, contudo a educação destinada às pessoas com deficiência se limitou à institucionalização desse segmento social, adotando novas formas de restrição delas. Essas instituições tinham como objetivo retirar os "desajustados" do convívio social e torná-los minimamente produtivos ao sistema capitalista. Na verdade, essas instituições especializadas se caracterizavam por "depósitos" daqueles que não correspondiam às demandas impostas pelo regime capitalista de acumulação. Assim, essas pessoas continuaram a serem excluídas do meio social, e a falácia liberal de oportunizar educação a todos continuou a servir como instrumento ideológico para naturalizar a desigualdade social.

Vale salientar que esses procedimentos não atingiram a todas as pessoas com deficiência, pois os filhos da burguesia dominante desfrutavam de uma educação sistematizada, gozando de uma vida familiar e de riquezas. De acordo com Bueno (1993, p. 70):

[...] aos cegos e surdos pobres se reservava trabalho manual imbecilizante, um arremedo de salário quando muito, ou senão um catre e um prato de comida. Os que não tiveram o infortúnio de nascerem pobres, marca muito mais significativa do que a surdez e a cegueira, apesar de sofrerem limitações impostas por suas deficiências, puderam, contudo, usufruir da vida familiar e da riqueza produzida.

No Brasil, o modelo de institucionalização das pessoas com deficiência seguiu os mesmos princípios dos congêneres europeus, tendo como marco histórico a criação do Imperial Instituto dos Meninos Cegos, em 1854, e o Instituto dos Surdos-Mudos, em 1857, ambos por iniciativa do governo imperial. Cabe ressaltar que a organização de instituições 
especializadas, em sua maioria filantrópico-assistenciais, que se estabeleceram no atendimento aos deficientes, fundamentaram duas tendências importantes para a educação especial que se constituía no país:

[...] a inclusão da educação especial no âmbito das instituições filantrópico-assistenciais e a sua privatização, aspectos que permanecerão em destaque em toda a sua história, tanto pela influência que elas exercerão em termos de política educacional como pela quantidade de atendimentos oferecidos (BUENO, 1993, p. 88).

Do mesmo modo, contribuiu para que a deficiência permanecesse no âmbito da caridade pública, impedindo, assim, que as suas necessidades se incorporassem ao rol dos direitos de cidadania (SILVA, 1986).

Visando consolidar o embate entre forças sociais e econômicas, no início da década de 1970 o modelo de institucionalização começa a ser contestado, dando lugar a um novo modelo, o de integração. O modelo de integração, implementado no país, fundamentava-se nos princípios da normalização e da racionalização. $\mathrm{O}$ primeiro ocupavase em normalizar as pessoas com deficiência, de maneira que elas pudessem se assemelhar aos demais cidadãos ditos "normais". O segundo tinha como objetivo a plena utilização dos recursos de que dispunha, para garantir a inserção dos sujeitos pertencentes a esse segmento social na lógica produtiva do capital, eliminando, assim, as despesas geradas nas instituições.

Nesse contexto, a educação especial implantada no país se ocupou com a normalização das pessoas com deficiência, a fim de garantir sua inserção social e reduzir os custos da manutenção das entidades, evidenciando a preocupação com a relação custobenefício às exigências do capital. De acordo com o discurso do assessor técnico James J. Gallagher, da Universidade de Carolina do Norte, encarregado na reorientação do sistema educacional brasileiro, em 1972:

Embora o custo da educação especial seja maior que o da educação regular, o retorno para a sociedade é grande em termos sociais e econômicos. Os Estados Unidos já vêm, em geral, aceitando o princípio segundo o qual as despesas com a educação de uma criança infratora são muito menores do que os custos com a sua manutenção durante o seu período de vida. Caso ela não receba treinamento (GALLAGHER, 1974, p. 99).

Levando em conta esses aspectos, não há de se ignorar que a ampliação efetiva no atendimento educacional às pessoas com deficiência foi, sem dúvida, impulsionada pela preocupação com a relação custo-benefício às exigências do capital. Ligando há um contexto histórico fortemente marcado pela teoria do capital humano, de elevação da produtividade pela qualificação técnica, tal modelo se legitimou em um projeto desenvolvimentista excludente, com vistas à integralização no sistema econômico.

Decorrente das transformações produtivas da década de 1970, com a crise estrutural do modelo fordista nos países ocidentais, um novo ciclo de acumulação capitalista se instaura, por meio da reestruturação produtiva toyotista e das reformas neoliberais. Nesse contexto, intensifica-se a conservação da dependência estrutural neoimperialista, a intensificação da exploração sobre os trabalhadores e o crescente desemprego estrutural, que engenhosamente é transformado pelo capital como consequência benéfica dos avanços tecnológicos e da falaciosa globalização. 
Assim, os elementos propulsores ao novo ciclo do capital, buscando implementar um novo padrão de acumulação por meio de um projeto hegemônico burguês, de instaurar um Estado de ideologia única, guiados pelos pressupostos "globalizantes", se estabelecem no cenário nacional pela ação dos organismos internacionais, como o Fundo Monetário Internacional (FMI), o Banco Mundial e a Organização Mundial do Comércio (OMC), na gerência e no controle das reformas políticas e sociais do país.

Tais reformas, assinaladas como possível síntese entre forças econômicas e sociais, despontaram no cenário brasileiro com a Constituição Federal de 1988, que representou um processo de luta pela redemocratização do país, conduzido por inúmeras mobilizações, de diversos movimentos sociais, desde os mais abrangentes até aqueles específicos, como o caso do movimento das pessoas com deficiência.

Assim, no final do século XX, configura-se a ampliação dos principais documentos internacionais na constituição da proposta de inclusão social, passando a indicar medidas que contribuíssem na construção de uma "sociedade inclusiva". Com efeito, na complexidade da trama em que é abalizado o discurso inclusivo, ganha destaque a propagação da diversidade cultural, que em prol do ideário neoliberal de tolerância multicultural escamoteia o antagonismo de classes, por meio da falácia de que a exclusão é cultural, elemento que produz a consciência social e coletiva em conformidade com as necessidades do capital.

Partindo do pressuposto da construção de uma "sociedade inclusiva", é introduzido um conjunto de medidas equitativas que reforçam a desigualdade substantiva por meio de ações compensatórias, visando à universalização da educação básica como consenso de equiparação à inclusão social. Dessa forma, a educação, mais uma vez, passa a ser referendada como solução aos problemas decorrentes da desigualdade estrutural capitalista.

Cabe assinalar que a ideologia de concessão do capital é incompatível com o modo de operação necessário à sua existência, pois ele não proporciona condições igualitárias, mas legitima o antagonismo hierárquico de classes. Mészáros (2004, p. 30) adverte que o capitalismo não permite a igualdade substantiva, apenas a camuflagem formal da desigualdade, que se faz passar por igualdade. Para tanto, os desafios que radicalizam o embate em torno do discurso inclusivo poderão ser equacionados se considerarmos as práticas sociais direcionadas à população como um todo, independente de gênero, raça, ou deficiência.

\section{LEGISLAÇÃO E A RESERVA NO MERCADO DE TRABALHO, PARA AS PESSOAS COM DEFICIÊNCIA}

As atuais transformações no mercado de trabalho têm se caracterizado pela profunda desigualdade na relação do trabalhador com o mercado. Essas relações, que, por sua vez, assinalam o antagonismo das classes, caminham lado a lado. As condições sociais oferecidas para a formação de pessoas com deficiência ainda envolve graves problemas, apesar de mudanças relevantes que têm ocorrido em tempos recentes. Os caminhos de solução não são vistos, naturalmente, de maneira uniforme; anunciam possibilidades, mas envolvem divergências, resistências e controvérsias.

No final do século $\mathrm{XX}$, as reformas impostas pela reestruturação produtiva do capital e a massificada luta popular por melhores condições de existência resultaram no aumento do conjunto dos registros legais e dos principais documentos internacionais, que, por meio das agências de fomento como o Banco Mundial e o Fundo das Nações Unidas para a Infância (UNICEF), mecanismos neoimperialistas, influenciaram na elaboração da legislação dos países em desenvolvimento. 
É nesse contexto, condicionado pelas políticas neoliberais, que a inclusão ${ }^{1}$ de pessoas com deficiência é proposta, ganhando forças com a declaração de Salamanca (1994), que teve um papel fundamental na organização das políticas para a inclusão das pessoas com deficiência, ao traçar linhas de ações em nível internacional, onde se ressalta a importância na adoção de medidas legislativas paralelas e complementares, que devem ser adotadas nos campos da saúde, bem-estar social, treinamento vocacional e trabalho, no sentido de promover apoio e gerar total eficácia à legislação educacional.

O Brasil, ao assumir sua adesão à Declaração de Salamanca, concretiza um compromisso junto às agências de fomento internacional, com o objetivo de estabelecer índices quantitativos de inclusão, como Kuenzer sinaliza:

Por força de políticas públicas "professadas" na direção da democratização, aumenta a inclusão em todos os pontos da cadeia, mas precarizam-se os processos educativos, que resultam em mera oportunidade de certificação, os quais não asseguram nem inclusão, nem permanência (2006, p. 880).

Tais políticas despontaram no cenário brasileiro com a Constituição Federal, que, em seu artigo 203, IV e V, garante a proteção e integração social das pessoas portadoras de deficiência. Nesse âmbito, fica incumbida aos Estados e Municípios a responsabilidade de criarem leis que protejam e amparem essas pessoas, inclusive no mercado de trabalho, que é onde elas mais sofrem preconceitos, por serem considerados inaptos para determinadas tarefas. Nesse aspecto, a LDB 9394/1996 sugere, em seu artigo 59 a oferta de:

Educação especial para o trabalho, visando a sua efetiva integração na vida em sociedade, inclusive condições adequadas para os que não revelarem capacidades de inserção no trabalho competitivo, mediante articulações com os órgãos oficiais afins, bem como para aqueles que apresentam uma habilidade superior nas áreas artísticas, intelectual ou psicomotora (BRASIL, 1996).

Nesse contexto, e acompanhando a tendência de igualdade e liberdade, foi publicado o Decreto $n^{\circ} 3.956 / 2001$, assinalando que as pessoas com necessidades especiais têm os mesmos direitos humanos e liberdades fundamentais que as demais, definindo como discriminação, com base na necessidade, toda diferenciação ou exclusão que possa impedir ou anular o exercício dos direitos humanos, de suas liberdades fundamentais de cidadão a qualquer indivíduo. Esse decreto deveria ter repercussão em todos os âmbitos sociais, e isso inclui o mercado de trabalho, pois ele exige uma cuidadosa interpretação nesse aspecto, do sentido de valorização da mão de obra das pessoas com deficiência, pois não basta ampliar a educação através da inclusão ${ }^{5}$, sem ter uma proposta para que essa clientela venha se sentir útil, sendo incluída socialmente também na sua área de formação.

Objetivando a ampliação do quadro de acesso à educação básica, em 2008 houve a aprovação do Decreto $n^{\circ} 6.571 / 2008$, revogado pelo Decreto $n^{\circ} 7611 / 2011$, que estabelece a garantia do acesso e permanência no ensino regular e o atendimento das necessidades educacionais especiais dos alunos, fortalecendo a inclusão educacional nas escolas públicas. Além da legislação supracitada, destacamos a prevalência de programas e ações desenvolvidas em âmbito nacional, pelo Ministério da Educação (MEC), com o objetivo de ampliar o número de matrículas na educação básica, ao atender à necessidade do governo em melhorar os indicadores nacionais da educação básica.

Essas ideias escamoteadas pelas estratégias inclusivas servem como base para ludibriar o trabalhador, quando, na realidade, o objetivo é ajustar o trabalhador com a falsa 
ideia de inclusão. Isso é defendido por Kuenzer (2001, p. 93) como o conjunto de estratégias que apenas conferem "certificação vazia", e por isso mesmo constituem-se em modalidades aparentes de inclusão que fornecerão a justificativa, pela incompetência, para a exclusão do mundo do trabalho, dos direitos e das formas dignas de existência.

Quanto à legislação que propõe a inclusão da pessoa com deficiência ao mercado de trabalho, temos como mote a Lei 7.853, de 24 de outubro de 1989, que dispõe sobre a Política Nacional para a Integração da Pessoa Portadora de Deficiência, assegurando às pessoas com deficiência o pleno exercício de seus direitos básicos, inclusive dos direitos à educação, à saúde, ao trabalho, ao lazer, à previdência social, ao amparo à infância e à maternidade, e de outros que, decorrentes da Constituição e das leis, propiciem seu bemestar pessoal, social e econômico.

Quanto ao âmbito da União, é assegurado o direito da pessoa com deficiência se inscrever em concurso público para provimento de cargos cujas atribuições lhe sejam compatíveis, sendo reservado até $20 \%$ das vagas oferecidas em concursos (art. $5^{\circ}, \S 2^{\circ}$, Lei $\left.\mathrm{n}^{\mathrm{o}} 8.112 / 90\right)$.

No que se refere às empresas do setor privado, a Lei $n^{\circ} 8.213$, de 24 de julho de 1991, esclarece, em seu Art. 93, que:

A empresa com 100 (cem) ou mais empregados está obrigada a preencher de $2 \%$ (dois por cento) a $5 \%$ (cinco por cento) dos seus cargos com beneficiários reabilitados ou pessoas portadoras de deficiência, habilitadas, na seguinte proporção:

I - até 200 empregados....................................................... $2 \%$;

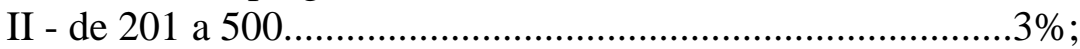

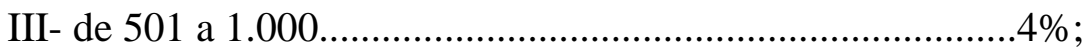

IV - de 1.001 em diante.........................................................5\%.

A lei supra, além de estabelecer cotas obrigatórias de vagas a serem respeitadas pelas empresas do setor privado, acrescenta que a dispensa do funcionário somente poderá ocorrer após contratação de substituto com condição semelhante. É admissível multa ${ }^{6}$ ao não cumprimento da Lei de Cotas, conforme estabelece o Ministro de Estado da Previdência Social, de acordo com o artigo 13 da portaria MPS n ${ }^{\circ} 727$, de 30 de maio de 2003, "o responsável por infração a qualquer dispositivo do Regulamento da Previdência Social (RPS) para qual não haja penalidade expressamente cominada".

Em detrimento ao cumprimento da lei de cotas, as empresas clamam ao Estado a responsabilidade social sobre a qualificação das pessoas com deficiência, no sentido de cuidar da educação ou da formação destas pessoas. De acordo com a advogada Ana Leticia Maier de Lima, do Popp\&Nalin Advogados Associados, a empresa não pode ser autuada nem multada por algo que não deu causa, como é o caso, em que "o Estado transferiu às empresas a responsabilidade social sobre os deficientes, mas não os habilita para o mercado de trabalho. Dessa forma, não há como falar em responsabilização dos empresários" ". Com isso, o capitalismo delega a responsabilidade ao Estado, supondo que, assim, as escolas tornar-se-iam mais sensíveis à dinâmica do mercado, de modo que forçam a rede pública de ensino a incorporar-se às leis de mercado e a competir (ANTUNES, 1999).

Segundo Barbosa (2008), a grande dificuldade em cumprir a Lei de Cotas $n^{\circ} 8.213$, art. 93, é a qualificação profissional, pois o sistema educacional para pessoas com deficiência é de péssima qualidade, ou seja, as pessoas com deficiência já vêm, desde a 
escola fundamental, sendo pouco e mal-atendidas na sua formação escolar, e essa "herança" será saturada para sua vida profissional.

Considerando o exposto, a qualificação exigida pelo mercado de trabalho, justificativa permanente da não contratação de pessoas com deficiência, escamoteia a desigualdade substantiva calcada na expansão do capital. Por meio do discurso da qualificação, o capital justifica a exclusão de grande parte de trabalhadores, pois o crescimento econômico na nova lógica estruturada pelo capital não requer a inclusão de amplos segmentos, mas sim a inclusão:

[...] das pessoas nos processos econômicos, na produção e na circulação de bens e serviços, estritamente em termos daquilo que é racionalmente conveniente e necessário à mais eficiente (e barata) reprodução do capital. E, também, ao funcionamento da ordem política, em favor dos que dominam (MARTINS, 1997, p. 20).

De acordo com a cartilha elaborada pelo Ministério do Trabalho e Emprego, que orienta sobre os procedimentos e o sistema de cotas para a inclusão de pessoas com deficiência no mercado de trabalho, uma empresa só tem a obrigação de contratar uma pessoa com deficiência desde que ela tenha acima de 100 funcionários, contudo a escassez de uma fiscalização eficiente, materializa-se em um não cumprimento da legislação, ou, em alguns casos, as empresas, optam em pagar a multa em detrimento ao cumprimento da lei de cotas, ao considerar os inúmeros fatores que, promovidos pela visão de lucro, acabam favorecendo a não contratação dessa mão de obra, ora considerada em primeiro plano desqualificada (SIMONELLI et al., 2011, p. 14).

Contudo, cabe destacar que a adesão por algumas empresas à Lei de Cotas configura-se na colonização do imaginário social, do "politicamente correto", ou seja, elas aderem à legislação por uma questão de marketing, pela necessidade ideológica de se cobrirem pelo manto da "responsabilidade social".

Do mesmo modo que se enfatiza a responsabilidade dos sujeitos por suas condições de trabalho, que se articula o discurso da qualificação, ou seja, do disciplinamento do trabalhador, é possível aferir que existe um imenso abismo que separa o discurso inclusivo da realidade material.

Do lado do mercado, um processo de exclusão includente que tem garantido diferenciais de competitividade para os setores reestruturados por meio da combinação entre integração produtiva, investimento em tecnologia intensiva de capital e de gestão e consumo precarizado da força de trabalho (KUENZER, 2001, p. 81).

Para alguns, o trabalho está relacionado não só à lógica do processo de trabalho, mas ao processo do conhecimento: pois o trabalhador que detém o conhecimento sofre menos nessa lógica aterradora do capital. Nessa perspectiva, a educação de interesse dos trabalhadores não deveria estar atrelada aos interesses do mercado, mas sim posicionada em detrimento à formação humanístico-científica. Nesse sentido, o grande desafio para Minayo (2004, p. 57) "é a articulação da 'cultura de resistência', de forma que ela se traduza em instâncias organizativas, objetivando mudanças nas relações de produção favoráveis aos trabalhadores". Sendo assim, as relações de trabalho necessitam de uma reflexão, buscando meios de resistir à imposição do sistema capitalista, tendo como desafio dar acesso ao saber humano sistematizado em uma perspectiva progressista de educação. 


\section{A CONJUNTURA DO MERCADO DE TRABALHO DAS PESSOAS COM DEFICIÊNCIA NO ESTADO DE RONDÔNIA}

A presente pesquisa teve como objetivo investigar o processo de inclusão das pessoas com deficiência no mercado de trabalho do Estado de Rondônia, com vistas a subsidiar a compreensão da efetividade da Lei $\mathrm{n}^{\circ}$ 8.213/91, na absorção da força de trabalho das pessoas com deficiência.

Segundo o censo do Instituto Brasileiro de Geografia e Estatística (IBGE) de 2010, a população do Estado de Rondônia é de 1.562 .409 habitantes, sendo que 22,1\% da população do Estado apresentam ao menos um tipo de deficiência.

A partir da amostragem do IBGE, da população com deficiência no Estado de Rondônia, foi conduzida a coleta de dados junto ao Ministério do Trabalho e do Emprego do Estado de Rondônia (MTE) e à agência do SINE do Estado de Rondônia. Primeiramente, foi consultado o Ministério do Trabalho e do Emprego do Estado de Rondônia (MTE), para verificar o número de empresas do setor privado do Estado de Rondônia com um quantitativo superior a cem funcionários, a quantidade de cotas para pessoas com deficiência (PCD) e o número de (PCD) contratadas, no ano de 2012. Isso levou à obtenção do resultado expresso na Tabela 1:

Tabela 1 - O total de empresas no Estado de Rondônia e o número de PCD empregados.

\begin{tabular}{ccccc}
\hline $\begin{array}{c}\text { Total de empresas no Estado } \\
\text { de Rondônia }\end{array}$ & $\begin{array}{c}\text { Empresas com 100 ou } \\
\text { mais empregados } \\
\text { RO }\end{array}$ & $\begin{array}{c}\text { Total de } \\
\text { Empregados }\end{array}$ & $\begin{array}{c}\text { Total de } \\
\text { Cotas (PCD) }\end{array}$ & $\begin{array}{c}\text { PCD } \\
\text { Contratados }\end{array}$ \\
\hline $\mathbf{8 9 . 7 6 6}$ & $\mathbf{3 0 6}$ & $\mathbf{9 9 . 2 0 1}$ & $\mathbf{3 . 6 1 7}$ & $\mathbf{7 5 3}$ \\
\hline
\end{tabular}

Fonte: Elaborado pelos autores, 2013.

Conforme os dados apresentados pelo Superintendente do Ministério do Trabalho e do Emprego do Estado de Rondônia, é possível aferir que a efetividade da lei está muito longe de ser cumprida. De acordo com os dados apresentados, das 306 empresas do setor privado com um quantitativo superior a cem funcionários, apenas $15 \%$ atendem à legislação. Na sequência da análise, verifica-se que das 3.617 vagas de cotas, destinadas às pessoas com deficiência, apenas $21 \%$ (753) da população-alvo dessa política estão ocupando vagas no mercado formal de trabalho, no Estado de Rondônia. De acordo com o Superintendente do Ministério do Trabalho e do Emprego do Estado de Rondônia, apesar da fiscalização feita pelo MTE, no Estado, muitas empresas articulam o não cumprimento da lei pela falta de capacitação e qualificação do público-alvo. Desse modo, eximem-se do cumprimento e até mesmo do pagamento da infração, por meio da justificativa da falta de profissionais com deficiência, qualificados para os postos de trabalho.

Diferente do discurso empregado pela qualificação, Kuenzer (2006) destaca que a nova forma de organização e gestão do trabalho reduziu os requisitos de qualificação do trabalhador e intensificou o uso da força de trabalho, explorando-o ainda mais. Assim, a justificativa de força de trabalho qualificada não condiz com o modo de produção vigente:

Pelo contrário, o trabalho da maioria está cada vez mais desqualificado, intensificado e precarizado, como resultado do novo regime de acumulação. Do que se conclui que, do ponto de vista da gestão empresarial, a recomposição da unidade do trabalho não passa de ampliação de tarefas do trabalhador, sem que isto signifique uma nova qualidade na formação, de modo a possibilitar o domínio intelectual da técnica (KUENZER, 2001, p. 90). 
O discurso hegemônico proclamado pelo capital aponta que a inserção do trabalhador depende de sua qualificação. Assim, se o trabalhador não tem sua inserção em um posto de trabalho, esse não o fez porque não se dedicou ou não se qualificou adequadamente, ou seja, a culpa do desemprego é do próprio trabalhador. Esse enfoque nas competências e capacidade de cada indivíduo em adquirir sua qualificação para conquistar sua posição no mercado de trabalho representa a promessa do pleno emprego na qual camufla o desemprego estrutural promovido pelo advento do processo de modernização econômica.

Perante os dados levantados pelo tem, foi pertinente a consulta à Agência Estadual do SINE, a fim de verificar a demanda e a oferta de vagas para pessoas com deficiência, no mercado de trabalho do Estado de Rondônia. Os dados fornecidos pela Agência estadual do SINE possibilitaram a obtenção do número de pessoas com deficiência cadastradas, encaminhadas e colocadas em postos de trabalho, bem como a demanda de vagas cadastradas no ano de 2012, conforme expresso na Tabela 2:

Tabela 2 - Número de pessoas com deficiência cadastradas na Agência do SINE do Estado de Rondônia no ano de 2012

\begin{tabular}{cccc}
\hline Cadastrados & Encaminhados & Colocados & Vagas cadastradas \\
\hline 317 & 94 & 10 & 85 \\
\hline
\end{tabular}

Fonte: Elaborado pelos autores, 2013.

Conforme tabela 1 o número de pessoas com deficiência, empregadas no ano de 2012, correspondem a 3\% do número de cadastros. Segundo o responsável pelo departamento de cadastro de pessoas com deficiência, da Agência estadual do SINE, ao ser questionado sobre a efetividade da Lei $\mathrm{n}^{\circ}$ 8.213/91 no Estado de Rondônia, informou que grande parte das empresas alega desconhecer a legislação, e somente após autuação do Ministério Trabalho e do Emprego (MTE) recorrem ao SINE para solicitar a disponibilidade de recursos humanos, para o cumprimento da lei.

Nesse sentido, a solicitação de cadastro de pessoas com deficiência é encaminhada ao SINE Estadual, perante uma série de exigências colocadas pelas empresas. Conforme consulta em alguns documentos destinados pelas empresas ao SINE, para contratação de pessoas com deficiência, constatou-se que as empresas exigem níveis de qualificação e requisitos preestabelecidos, o que, de acordo com o responsável pelo departamento de cadastro de pessoas com deficiência do SINE, dificulta a inserção desses sujeitos no mercado de trabalho.

No entanto, em uma análise mais apurada, é possível constatar que a qualificação exigida por essas empresas parte do princípio da experiência, ou seja, privilegia a qualificação por meio da aprendizagem pela experiência, por um conhecimento tácito, isto é, "qualificar-se na ação".

De acordo com os documentos consultados, o nível de escolarização exigido pelas empresas se limita aos anos iniciais do ensino fundamental; já a experiência profissional perpassa um ano. Dessa forma, o nível de qualificação se resume:

[...] a observar e repetir até memorizar as "boas práticas" dos trabalhadores mais experientes, bastando inserir desde logo o futuro trabalhador na situação concreta de trabalho, mesmo sem que ele se aproprie de categorias teórico-metodológicas que lhe permitam analisá-la e compreendê-la para poder intervir com competência (KUENZER, 2006, p. 905). 
Nessa perspectiva, o processo educativo, perante a nova forma de organização produtiva do capital, transfere a valorização do conhecimento escolar clássico para a valorização do conhecimento tácito, do cotidiano do aluno em detrimento de um conhecimento científico.

Cabe destacar que a exigência de qualificação por parte das empresas é uma artimanha utilizada para burlar a legislação, já que o não atendimento ao perfil solicitado pelas empresas implica na justificativa da falta de força de trabalho qualificada. Assim, os excluídos e desempregados são culpabilizados ou, no mínimo, responsabilizados por não estarem preparados para fazer frente às exigências do mercado de trabalho.

De acordo com o responsável pelo departamento de cadastro de pessoas com deficiência do SINE, uma saída para a efetividade na legislação de cotas seria o incentivo tributário por parte do Estado. Pois muitas empresas alegam que a redução e a concessão de benefícios fiscais para as empresas privadas que empregam pessoas com deficiência fomentariam a efetividade do cumprimento da lei. Na Argentina, há concessão de incentivos fiscais ao setor privado para a contratação de pessoas com deficiência, sendo reduzidas em $50 \%$ as contribuições previdenciárias dos empregadores. Contudo, a inclusão proposta por incentivos fiscais intensifica a tese conservadora liberal, aprimorando o voucher ou a carta de crédito às empresas, na garantia de emprego à população "excluída", ou grupos vulneráveis.

Essa medida representa a égide neoliberal, que desmonta a face social do Estado, na busca da maior eficiência das políticas públicas pela privatização, através do repasse do estado para o setor privado, abalizando as concepções e práticas sociais mercantis. Igualmente o trabalho para as pessoas com deficiência não mais é direito social do sujeito, mas um serviço mercantil, posto no balcão de negócios.

\section{CONSIDERAÇÕES FINAIS}

Entendemos que a compreensão do particular só pode ser alcançada a partir do universal. Dessa forma, procuramos conduzir a análise da absorção das pessoas com deficiência no processo produtivo, com base na atual conformação da reestruturação produtiva do capital.

Dentro deste contexto, ao se desenvolver o presente trabalho investigativo, se norteou pela questão maior a ser investigada: qual é a efetividade da Lei ${ }^{\circ} 8.213 / 91$ no Estado de Rondônia?

Com base no levantamento de dados da pesquisa, concluímos que o discurso hegemônico proclamado pelo capital responsabiliza os trabalhadores por não estarem qualificados para fazer frente às exigências do mercado de trabalho, o que exime grande parcela das empresas do não cumprimento da Lei $n^{\circ}$ 8.213/91. Assim, a inclusão das pessoas com deficiências no mercado de trabalho se constitui apenas na defesa do princípio, não sendo acompanhada por uma política que de fato garanta o cumprimento da lei.

Contudo, a ação destrutiva contra a força humana de trabalho e, consequentemente, a dificuldade de inserção no processo produtivo não são apenas um problema exclusivo daqueles tradicionalmente reconhecidos por sua condição de "vulnerabilidade social", dentre eles as pessoas com deficiência, mas um problema do enorme contingente de trabalhadores precarizados ou mesmo à margem do processo produtivo. Isso porque a existência dessa camada de trabalhadores excluídos do processo produtivo intensifica as fileiras do exército de reserva, assegurando ao capital a submissão daqueles que vivem do trabalho. 
Perante as demandas imposta pela lógica da reestruturação produtiva do capital, intensifica-se a exclusão, que ideologicamente se camufla pela hegemonia do capital como o movimento pela inclusão, em prol de um ajustamento a um estado de ideologia única. Tal movimento é gerido pelo princípio do respeito à diversidade e valorização das diferenças, gerando, assim, a falsa impressão de igualdade, mas que, na verdade, tem como objetivo naturalizar a desigualdade estrutural econômica, na medida em que se reduz a crítica sobre ela. Dessa maneira, o capital atenua o impacto das crises e administra a possível articulação social, na qual se faz passar pela possibilidade de maior participação dos diferentes grupos sociais, que falaciosamente gera a sensação de maior igualdade, negando a existência de elementos que compõem a materialidade das classes sociais.

Contrapondo, de forma incisiva, a análise desenvolvida neste trabalho, a estratégia do movimento de inclusão, conclui-se que esta é apenas proclamada no sentido ideológico de dissimular a realidade, pois ela jamais poderá ser alcançada dentro dessa ordem social, ao considerar que as condições que prevalecem à lógica interna do capital, tem como essência a exclusão.

Por fim, compreendemos que as estratégias de lutas se potencializam perante o caráter contraditório que emerge da presente crise do capital, a qual, dentro da materialidade histórica, possibilita que seja forjada a emancipação do homem e a reafirmação da superação dessa ordem com vistas à socialização dos meios de produção.

\section{REFERÊNCIAS}

ALBORNOZ, Suzana. O que é Trabalho. São Paulo: Brasiliense, 2008.

ANTUNES, Ricardo. Os sentidos do Trabalho: ensaio sobre a afirmação e negação do trabalho. São Paulo: Boitempo, 1999.

BACZINSKI, Alexandra V. de M., PITON, Ivania M., TURMENA, Leandro. Editorial. Revista HISTEDBR, Campinas, n. 31, p. 1-3, set. 2008. Disponível em: $<$ http://www.histedbr.fae.unicamp.br/revista/edicoes/31/editorial.html>. Acesso em: 20 de março de 2013.

BARBOSA, Ana Maria. Cotas, empresas e pessoas com deficiência. Paraná, Coordenadora do programa "Agenda Deficiência" e diretora de Comunicação de Rede SACI (Sociedade Apoio, Comunicação e Informação), 2008. Disponível em: $<$ http://carreiras.empregos.com.br/comunidades/rh/artigos/141204cotas_deficientes_saci.shtm>. Acesso em: 3 maio 2013.

BELlUZZO, L. G. Capital financeiro e Desigualdade. Le Monde Diplomatique Brasil, São Paulo, ano 6, n. 65, p. 16-17, dez, 2012.

BRASIL. Constituição Federal 1988. Brasília: Senado, 1988a.

BRASIL. Lei $N^{\circ}$ 9.394, de 20 de dezembro de 1996. Estabelece as diretrizes e bases da educação nacional. Brasília: Senado, 1996.

BRASIL. A inclusão de pessoas com deficiência no mercado de trabalho. 2. ed. Brasília: MTE, SIT, 2007.

BRASIL. Decreto $\mathrm{n}^{\mathrm{o}}$ 3.956, de 08 de outubro de 2001. Promulga a Convenção Interamericana para a Eliminação de Todas as Formas de Discriminação contra as Pessoas Portadoras de Deficiência. Disponível em: 
<http://www.planalto.gov.br/ccivil_03/decreto/2001/d3956.htm>. Acesso em 30 de março de 2013.

BRASIL. Decreto ${ }^{\circ} 7611$, de 17 de novembro de 2011. Dispõe sobre a educação especial, $o$ atendimento educacional especializado e dá outras providências. Disponível em: <http://www.planalto.gov.br/ccivil_03/_Ato2011-2014/2011/Decreto/D7611.htm\#art11>. Acesso em 02 de abril de 2013.

BRASIL. Lei $\mathrm{n}^{\circ} 7853$, de 24 de outubro de 1989. Dispõe sobre o apoio às pessoas portadoras de deficiência, sua integração social, sobre a Coordenadoria Nacional para Integração da Pessoa Portadora de Deficiência - Corde, institui a tutela jurisdicional de interesses coletivos ou difusos dessas pessoas, disciplina a atuação do Ministério Público, define crimes, $e$ dá outras providências. Disponível em: <http://www.planalto.gov.br/ccivil_03/leis/17853.htm>. Acesso em 04 de abril de 2013.

BRASIL. Lei $\mathrm{n}^{\circ}$ 8.112, de 11 de dezembro de 1990. Dispõe sobre o regime jurídico dos servidores públicos civis da União, das autarquias e das fundações públicas federais. Disponível em: <http://www.planalto.gov.br/ccivil_03/leis/18112cons.htm〉. Acesso em 12 de abril de 2013.

BRASIL. Lei $\mathrm{n}^{\mathrm{o}}$ 8.213, de 24 de julho de 1991. Dispõe sobre os Planos de Benefícios da Previdência Social e dá outras providências. Disponível em: <http://www.planalto.gov.br/ccivil_03/leis/18213cons.htm>. Acesso em 02 de abril de 2013.

BRASIL. Lei $\mathrm{n}^{\circ}$ 8.213, de 24 de julho de 1991. Dispõe sobre os Planos de Benefícios da Previdência Social e dá outras providências. Disponível em: <http://www.planalto.gov.br/ccivil_03/leis/18213cons.ht>. Acesso em: 20 de março de 2013.

BUENO, José, Geraldo, Silveira. Educação especial brasileira: integração/segregação do aluno diferente. São Paulo: EDUC, 1993.

DECLARAÇÃO DE SALAMANCA. Sobre princípios, políticas e práticas na área das necessidades educativas especiais. Salamanca, Espanha 10 de junho de 1994. Disponível em: <http://portal.mec.gov.br/seesp/arquivos/pdf/salamanca.pdf>. Acesso em: 20 jan. 2013.

ENGELS, Friederich. A origem da família, da propriedade privada e do estado. Rio de Janeiro: Civilização Brasileira, 1984.

GALLAGHER, J. J. Planejamento da educação especial no Brasil. In: PIRES, Educação especial em foco. Rio de Janeiro: Centro Brasileiro de Pesquisas Educacionais, 1974.

IBGE - Instituto Brasileiro de Geografia e Estatística. Disponível em: <http://www.ibge.gov.br/estadosat/perfil.php?sigla=ro>. Acesso em: 2 mar. 2013.

KUENZER, Acácia Zeneida. Exclusão includente e inclusão excludente: a nova forma de dualidade estrutural que objetiva as novas relações entre educação e trabalho. In: LOMBARDI, José Claudinei; SAVIANI, Dermeval; SANFELICE, José Luis. Capitalismo, trabalho e educação. SP: Autores Associados, 2001. p. 77-95.

KUENZER, Z. A. A educação profissional nos anos 2000: a dimensão subordinada das políticas de inclusão. Educação e Sociedade, Campinas, v. 27, n. 96, esp., p. 877-910, out. 2006.

MARTINS, J. S. Exclusão social e a nova desigualdade. São Paulo: Paulus, 1997. 
MARX, Karl. Miséria da Filosofia. Portugal- Estampa Lisboa 1978.

MARX, Karl; ENGELS, Friedrich. Manifesto do Partido Comunista. São Paulo: Cortez, 1998.

MARX, Karl. O capital. São Paulo: Nova Cultural, 1985. v. II.

MÉSZÁROS, István. O poder da ideologia. São Paulo: Boitempo, 2004.

MINAYO GOMES, Carlos. Processo de trabalho e processo de conhecimento. In: MINAYO GOMES, Carlos et al. Trabalho e conhecimento: dilemas na educação do trabalhador. 5. ed. São Paulo: Cortez, 2004.

RAMOS, Alexandre L. Acumulação Flexível, Toyotismo e Desregulamentação do Direito do Trabalho. In: ARRUDA JUNIOR, Edmundo Lima de (Org.). Globalização, neoliberalismo e o mundo do trabalho. Curitiba: EDIBEJ, 1998. p. 60-76. v. 1.

SAVIANI, Demerval. Escola e democracia: teorias da educação, curvatura da vara, onze teses sobre a educação política. 37. ed. Campinas, SP: Autores Associados, 2005 (Polêmicas do nosso tempo, v. 5).

Trabalho e educação: fundamentos ontológicos e históricos. Revista Brasileira de Educação, Campinas- SP, v. 12, n. 34, p. 152-165, jan./abr. 2007.

Pedagogia histórico-crítica: primeiras aproximações. 10. ed. São Paulo: Ed. Autores Associados, 2008.

SILVA, Otto Marques da. A epopeia ignorada: a pessoa deficiente na história do mundo de ontem e de hoje. São Paulo: CEDAS, 1986.

SIMONELLI, Angela Paula and CAMAROTTO, João Alberto. Análise de atividades para a inclusão de pessoas com deficiência no trabalho: uma proposta de modelo. Gestão $e$ Produção. [online]. 2011, vol.18, n.1, pp. 13-26. ISSN 0104-530X.

1 - UNIR geferrazzo@ hotmail.com

2 - UNIRFrutuoso12@gmail.com

3 - UNIR Marroco 43@ hotmail.com

${ }^{4}$ - UNIRmarcooliveiragomes@ yahoo.com.br

${ }^{5}$ Há de se conceituar aqui o termo inclusão, que, no sentido etimológico, significa "conter em, fazer parte de". Assim, incluir no mercado de trabalho significa dar emprego e fazer com que o trabalhador se sinta parte daquilo que produz.

${ }^{6}$ Multa variável de $\mathrm{R} \$ 991,03$ a $\mathrm{R} \$ 99.102,12$.

7 Disponível em: <http://www.conjur.com.br/2011-abr-04/empresa-nao-pagar-multa-nao-preencher-cotadeficientes>. Acesso em: 8 mar. 2013.

Recebido: $\quad$ outubro-13 Aprovado: dezembro-14 